\title{
Experimental Study on Isothermal Forging Technology for a Complex-Shaped Titanium Alloy Wing
}

\author{
Jiang Hongyan', Cheng Feng ${ }^{2}$ \\ ${ }^{1}$ Jiangsu University of Science and Technology, Zhangjiagang 215600, China; ${ }^{2}$ Jiangnan University, Wuxi 214122, China
}

\begin{abstract}
The complex-shaped Ti-6Al-4V alloy is widely used in the aerospace engineering and automobile industry. However, because of its high hardness, easy adhesion, large dimension and high precision, it is a great deal of cost of raw materials, and besides, it is difficult to machine by the traditional manufacturing methods unless it uses special cutting tools. In this study, a closed isothermal forging process was adopted for precision forming of the wing. The rational billet shapes were estimated by flow simulation experiment, and then mechanical property, forming ability, process parameters of the Ti-6Al-4V wing were studied by the isothermal forging tests to meet performance targets. The results show that compared with the titanium wing formed by conventional methods, the wing made by isothermal forging remarkably improves mechanical performances, and material utilization increases from $13 \%$ to $50 \%$. During the isothermal forging process of Ti- $6 \mathrm{Al}-4 \mathrm{~V}$, the flake $\alpha$ grains at $950{ }^{\circ} \mathrm{C}$ are transformed to $\beta$ grains in the matrix; while the progress of transformation diminishes when the forging temperature decreases to $900{ }^{\circ} \mathrm{C}$.
\end{abstract}

Key words: titanium alloy; complex-shaped wing; isothermal forging; experimental study

Titanium alloys are widely applied in aeronautics, chemistry, shipbuilding, medical materials and other areas due to low density, high strength, toughness and good oxidization resistance at high temperatures ${ }^{[1-4]}$. For a long time, the manufacturers of automobile and aircraft have been seeking the possibility of using titanium alloys to increase the engine power and minimize the weight of moving parts ${ }^{[5,6]}$. However, the more immediate worry is that high cost of raw materials and hard-forming character ${ }^{[7]}$ may restrain the widespread use of titanium material in automobile industry.

In recent years, an isothermal forging technology has been applied in forging titanium alloys, which can produce a forging reaching or closely approaching the geometry and size of the complex-shape finished part ${ }^{[8-10]}$. Compared with traditional forging processes, it has many excellent advantages, such as great reduction of raw materials, significant improvement in dimensional precision and surface finish, and remarkable enhancement in mechanical properties of products ${ }^{[1,12]}$. Therefore, it can meet the demands of mechanical properties, and dimension tolerance of forgings in the aerospace and automobile industry.
As shown in Fig.1, the Ti-6Al-4V wing with large dimension, variable cross-section asymmetric structure and high precision, is a key component in the fields of automobile and aviation industries. It mainly consists of four parts: lug, bearing center hole, ribbed slab and airfoil. With conventional machining methods, however, it is difficult to machine because of its high hardness, hardening processing and easy adhesion $^{[13,14]}$. Other problems, such as low material utilization ratio is only $1 / 6$, ensuring accuracy and high cost aren't also solved satisfactorily ${ }^{[7]}$. Therefore, isothermal forging process is adopted for precision forming, increasing material utilization ratio by $50 \%$ and realizing "less cutting and no cutting". For isothermal forging of Ti-6Al-4V alloy, the material mechanical property and microstructures are influenced by the $\beta$-transition temperature ${ }^{[15]}$. As is well known, between 890 and $960^{\circ} \mathrm{C}$, very noticeable Hall-Petch behaviors of Ti-6Al-4V alloy are noted in the work by Luo and $\mathrm{Ye}^{[10]}$. Thus, in the present work, the influence of isothermal forging temperature $\left(900\right.$ and $\left.950^{\circ} \mathrm{C}\right)$ is studied to analyze mechanical property, forming ability and microstructures of the Ti-6Al-4V wing component mentioned above. It 


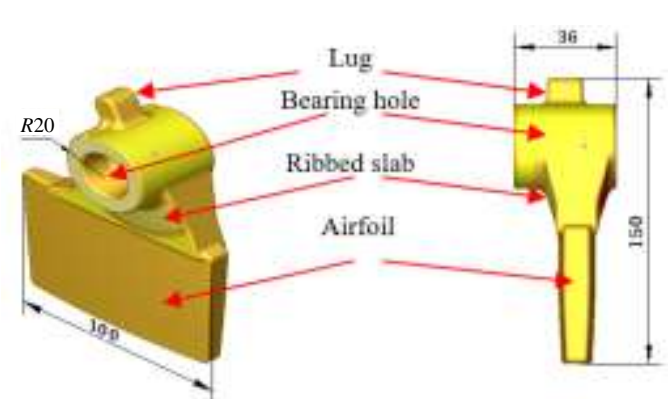

Fig. 1 Ti-6Al-4V wing component

was practical to proceed in two steps: lead flow simulation experiment and then titanium alloy isothermal forging experiment.

\section{Flow Simulation Experiment of Lead Billets}

\subsection{Experimental process}

Lead at ambient temperatures is very similar to Ti-6Al-4V at the temperature of $900{ }^{\circ} \mathrm{C}$ by similar theories ${ }^{[16]}$. With the purpose of not only estimating billet shapes rationally but preliminary proving the feasibility of isothermal forging process of the titanium alloy wing at a low cost, therefore, it was necessary to at first carry out lead flow simulation experiment before titanium alloy isothermal forging experiment.

In lead flow simulation experiment, five schemes of lead billet were worked out to meet the demand of forging. In the market, the suppliers can provide two kinds of raw materials: plates and bars. In the study, the geometries A, B and C were plates and the geometries $\mathrm{D}$ and $\mathrm{E}$ were bars. As shown in Fig.2, the first three billets (A, B, C) were manufactured by plates (34 mms thick) and the other billets $(\mathrm{D}, \mathrm{E})$ by bars $(40$ mms diameter). Furthermore, the billets $\mathrm{C}$ and $\mathrm{E}$ were designed as the lug in the top to make the metal flow into the die cavity more easily during forming. Because of a closed mould with a flash slot, the volume for each billet equals to the sum of forging volume and a half flash slot volume. The detailed dimensions are computed and obtained according to the dimensions of the forging component shown in Fig.1. Fig. 3 shows a simple die structure mainly made up of three parts (top die, bottom die and die sleeve), which are made by common steel (1045). The lead flow simulation experiments were carried out at oil hydraulic press with maximum pressure $100 \mathrm{~T}$ at ambient temperature, and the skin of billets and the cavity surfaces of the mold were lubricated by engine oil in the experiment.

\subsection{Experimental results}

As shown in Fig.4, experimental studies demonstrate that the billets A, B and D were difficult to fill the mould cavity due to their inappropriate shapes of billet while the billets $C$ and $\mathrm{E}$ showed better forging effects and more effective product quality because of their optimum features with a top lug. Red marks (Fig.4a) demonstrated that A was the worst of all billets in filling desired shapes of the lug, the bearing center hole and the airfoil due to an insufficient flow of metal, and the defects of folding cracks were also found at the end of the surfaces of the airfoil. With slightly better forming effects than A, the incomplete filling only appeared in positions of the lug and the bearing center hole for B and D. Furthermore, contrast to the billet $\mathrm{C}$ made by plates, the billet $\mathrm{E}$ made by bars with a cylindrical surface could more greatly reduce production cost and be more suitable for mass production in industrialization.

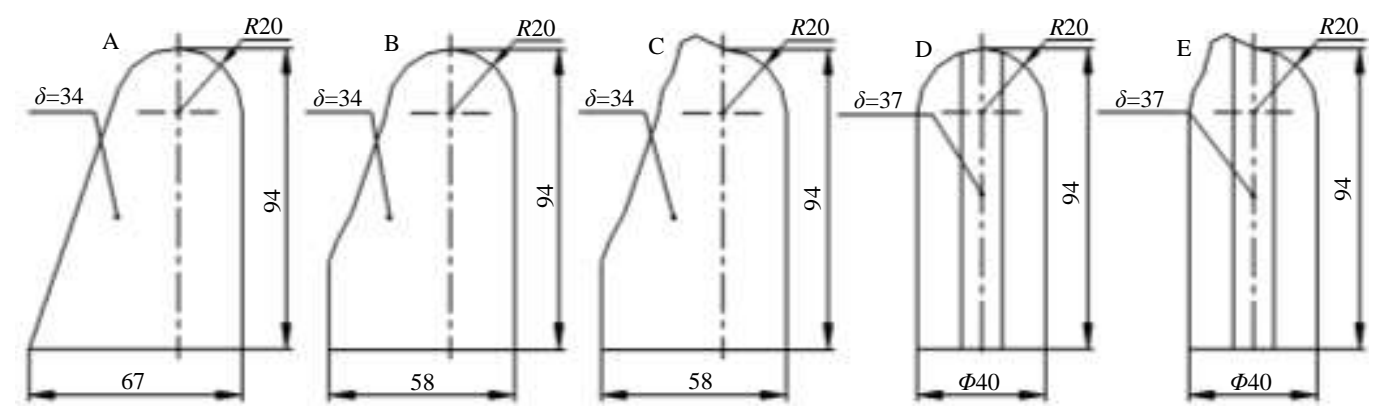

Fig. 2 Lead billets A, B, C, D, E for flow simulation experiment

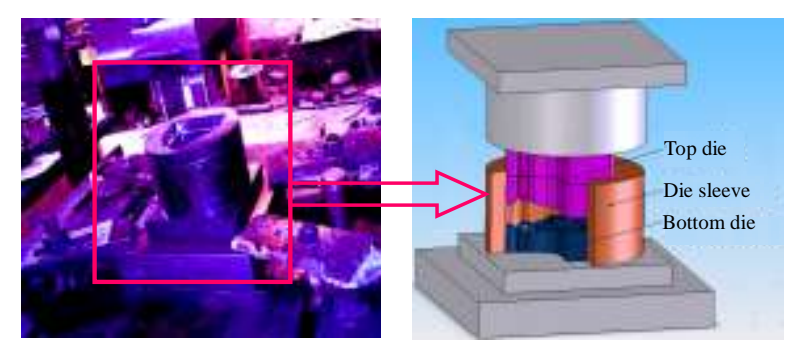

Fig.3 Schematics of lead flow simulation experimental apparatus
On the basis of the above, for the isothermal forging experiment, the optimizing shape of titanium billet $\mathrm{E}$, the 5th kind of billet (Fig.2) was preliminarily estimated in the first stage. The typical features were with a top lug and a cylindrical surface, which are different from other billets. In addition, owing to plenty of flashing loss caused by the machining error of mould, the two Ti-6Al-4V billets with different volume (0.5 times and 0.8 times volume of flash slots)) were used to test in the next stage. 


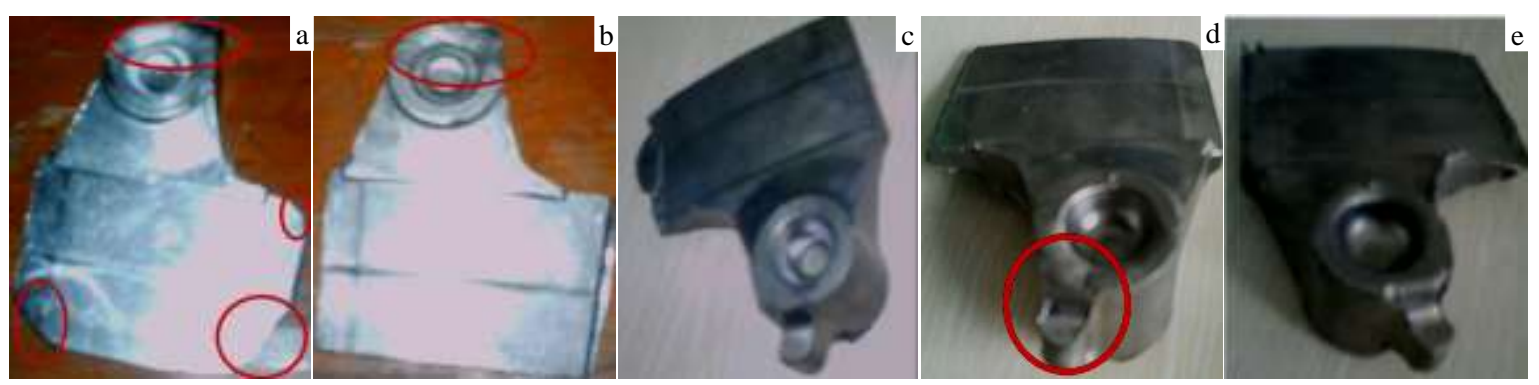

Fig.4 Forgings formed in flow simulation experiment of the lead billets A (a), B (b), C (c), D (d) and E (e)

\section{Isothermal Forging Experiment of Ti-6Al-4V Billets}

\subsection{Experimental process}

The Ti-6Al-4V wing has a complex outer face which consists of specially shaped lug, deep bearing hole, and a rather large airfoil surface. For this complex-shaped forging, as shown in Fig.5, the isothermal forging process adopted a closed isothermal forging to get a high material utilization ratio. Because of a high forging temperature for the Ti-6Al-4V alloy, the three key parts, in this mold, such as the top die, the bottom die and die sleeve, were made of high-temperature nickel-based alloy material (K403), which were formed by precision casting process. More importantly, the top die fixed to top die plate could move up and down in the die sleeve because a clearance $(0.1 \mathrm{~mm})$ existed between them; on the contrary, the bottom die could freely be pushed out from the die sleeve so as to take out the billet conveniently after forging. Moreover, cavity surfaces of the mold with flash slots were located in the top die and the bottom die to accommodate the redundant metal, and air vents were drilled on the upper and lower end face to rapidly vent large quantity air. In addition, the billet was heated up through an outer resistance furnace while the die used an induction heating furnace with outer control cabinet that could control the temperature automatically. This outer control cabinet was made up of supply, capacitor banks, voltage changer, thermocouple, thermometer and so on. The isothermal forming process maintained a constant temperature and slow strain rate, which could effectively improve the homogeneity of metal flow and decrease the deformation pressure on the material. In order to protect the hydraulic press and the all experimental apparatus, the thermal baffles named "aluminum silicate fiberboard" and top and bottom cooling plates with circulating water cooling system were used to provide high-temperature isolation.

The experiment was carried out on an isothermal forging hydraulic press (THP10-630) with nominal working pressure 630 t. Based on the results of lead flow simulation experiment, the two Ti-6Al-4V billets with different volumes (as mentioned before) were prepared for experiment. Before forging, the billet was heated in the resistance furnace, and a glass lubricant (FR6) layer of $0.3 \mathrm{~mm}$ thick was uniformly
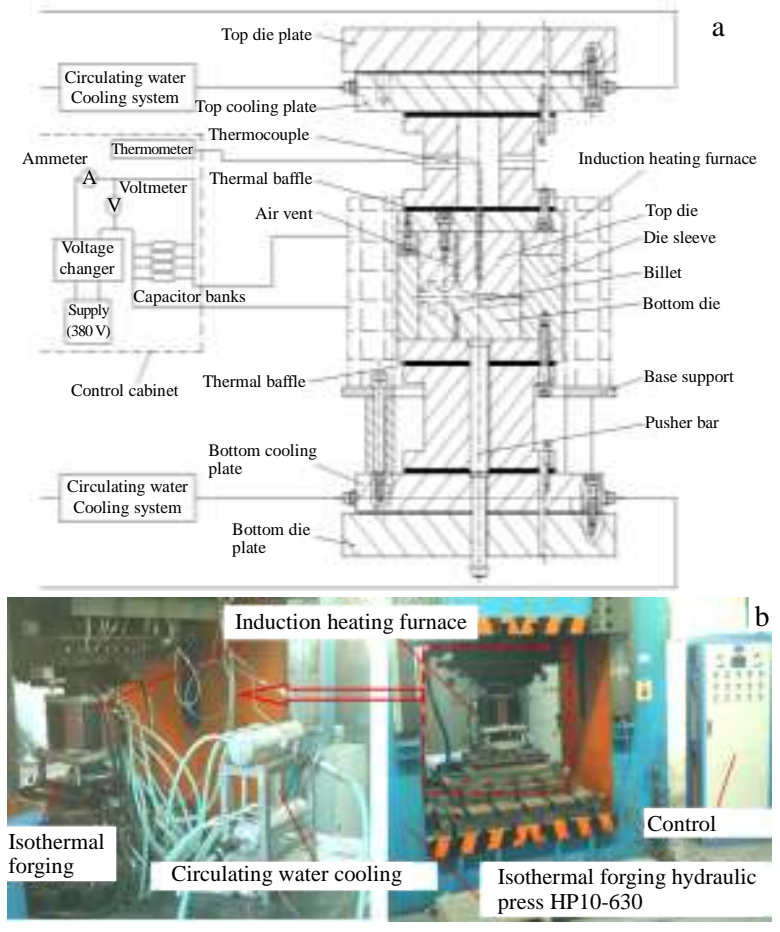

Fig.5 Isothermal forging mould (a) and experimental apparatus (b) for Ti-6Al-4

sprayed on the working surfaces of it when its surface temperature was heated up to $180^{\circ} \mathrm{C}$. Afterward, the billet was put into the furnace again and heated up to $900{ }^{\circ} \mathrm{C}$. Using induction heating furnace, meanwhile, the mould was heated on the press and also sprayed uniformly by the glass lubricant (FR6) at $180{ }^{\circ} \mathrm{C}$, and then it was again heated up to 900 950 ${ }^{\circ} \mathrm{C}$ after nearly $2.5 \mathrm{~h}$. After $40 \mathrm{~min}$ of heat preservation, the billet was taken out to transfer onto the hot moulds to slowly forge at the speed of $0.1 \mathrm{~mm} / \mathrm{s}$. At the end, the forging was taken out to cool naturally in the air and remaining glass films were removed by chemical processing.

\subsection{Experimental results}

In isothermal forging tested conditions, two forgings were all forged successfully and there were no defects (such as crack, wrinkle, scrape and pit) observed inside or outside of 
the specimen even by ultrasonic testing and macroscopic examination, which indicated the excellent fluidity of isothermal forging for Ti-6Al-4V alloys. For the purpose of evaluating the effect of isothermal forging on the material properties quantificationally, a series of mechanics performance tests and hardness test were conducted based on the two kinds of the Ti-6Al-4V specimen under conventional forging and isothermal forging conditions. Fig.6a shows sampling location for isothermal forging Ti-6Al-4V wing component by the billet A because an airfoil surface is the main bearing position in real working conditions. Fig.6b illustrates the tensile test piece number (1\#, 2\#, 3\#), and their effective diameter is $8 \mathrm{~mm}$ and effective length is $30 \mathrm{~mm}$. For a Ti-6Al-4V specimen without forging, the tensile test piece number is defined as 4\#. Meanwhile, using universal testing machine (WAW-Y500) and optical Brinell hardness tester (HBU-3000), yielding strength, tensile strength, elongation, reduction of cross section etc. were tested in according with China GB/T228-2002 and GB/T231-1984 standard. The results of mechanical performance tests are shown in Table 1.

\section{Discussion}

\subsection{Forging temperature}

In two experiments, isothermal forging temperature curves measured by thermocouple are shown in Fig.7. Four roughly stages were found when heating mould: I-preliminary heating $\left(0 \sim 180{ }^{\circ} \mathrm{C}\right)$, II-interrupting heating (II spraying lubricant), III-rapid heating $\left(180 \sim 900^{\circ} \mathrm{C}\right), \mathrm{IV}$-isothermal forging. In the first stage, the mould was preheated to $180{ }^{\circ} \mathrm{C}$ soon for spraying lubricant on the cavity surfaces subsequently. The most important stage of all was the fourth stage because of a constant temperature control between $900{ }^{\circ} \mathrm{C}$ and $950{ }^{\circ} \mathrm{C}$. According to Fig.7, the finish forging temperature of the billet

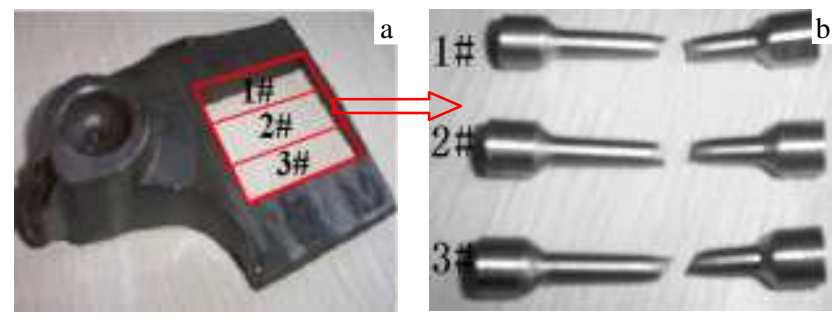

Fig.6 Tensile sampling location (a) and tensile test pieces (b) (1\#, 2\#, 3\#)

Table 1 Results of mechanical performance tests

\begin{tabular}{cccccc}
\hline Sample & Length/mm & UTS/MPa & YS/MPa & El/\% & $\begin{array}{c}\text { Brinell } \\
\text { hardness }\end{array}$ \\
\hline $1 \#$ & 30 & 985 & 925 & 11.5 & $300 \mathrm{HBW}$ \\
$2 \#$ & 30 & 985 & 925 & 13.5 & $5 / 750 / 30$ \\
$3 \#$ & 30 & 980 & 925 & 14.5 & \\
\hline \multirow{2}{*}{$4 \#$} & 30 & 895 & 825 & 10 & $195 \mathrm{HBW}$ \\
& & & & & $5 / 750 / 30$ \\
\hline
\end{tabular}

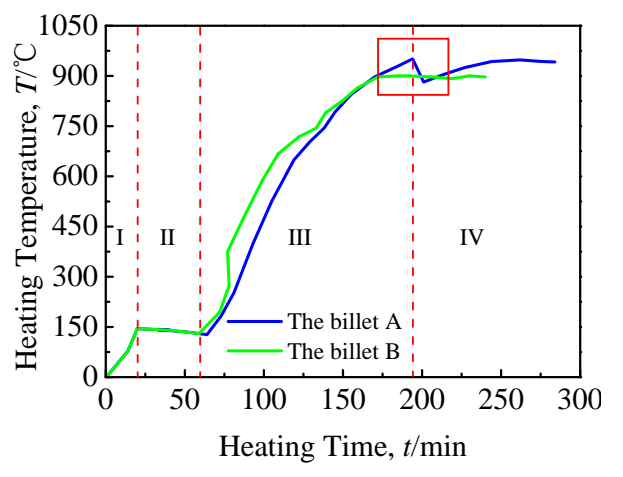

Fig.7 Isothermal forging temperature curves measured by thermocouple for the billet A and the billet B

A was slightly different from that of the billet $\mathrm{B}$, and the former was forged at $950{ }^{\circ} \mathrm{C}$ while the latter at $900^{\circ} \mathrm{C}$. As a result, it was proved that the Ti-6Al-4V alloys had the excellent dispersivity and fluidity between 900 and $950{ }^{\circ} \mathrm{C}$, but it was notable that phase changes, (hydrogen embrittlement, alpha embrittlement, etc) occurred at the superficial zone if the forging temperature was too high. Besides, in the test of the billet A, a temperature drop of the blue line (see red mark) appeared in the early forth stage because time was delayed due to the operation of the mistake when the preheated billet was put into the mould. So then it took some time to reach forging temperature of $950^{\circ} \mathrm{C}$ but it didn't affect the experiment results. However, for the test of the billet B, the last mistake was avoided and the continuous heating temperature curve was plotted by the green line.

\subsection{Volume of flash slots}

The two Ti-6Al-4V billets with different volumes ( 0.5 times and 0.8 times volume of flash slots) are calculated as follows: the volume of the product was $150815 \mathrm{~mm}^{3}$, the volume of the flash was $4404 \mathrm{~mm}^{3}$, coefficients of thermal expansion for the billets (Ti-6Al-4V) and sleeve die (K403) are 0.010 and 0.014 when heating them from room temperature to $900{ }^{\circ} \mathrm{C}$, the volume of billet A (0.8 times volume of flash slots) is $(150815+4404 \times 0.8) \times\left[1+\left(1.0114^{3}-1.010^{3}\right)\right]=156236 \mathrm{~mm}^{3}$, and the volume of the billet $\mathrm{B}$ ( 0.5 times volume of flash slots) is $(150815+4404 \times 0.5) \times\left(1+\left(1.014^{3}-1.010^{3}\right)\right)=154899 \mathrm{~mm}^{3}$.

Fig. 8 shows the final integral forging figure of the billet $\mathrm{A}$ and the billet B, which well correspond with the forging lead specimen shown in Fig.4e. Compared with the billet A, more flash with uneven thickness were made by the billet $\mathrm{B}$ at the places marked by the hidden line, which was caused by the machining error of clearance between the sleeve die and the top die. Meanwhile, it was confirmed that Ti-6Al-4V wing component had been forged successfully with less 0.5 times volume of flash slots, and in fact, more volume of flash slots would lead to the waste of raw materials. Furthermore, in forging process with a slow forging speed of $0.1 \mathrm{~mm} / \mathrm{s}$, the slider pressure was $12 \mathrm{MPa}$ (310 tonnes) for the billet A while 

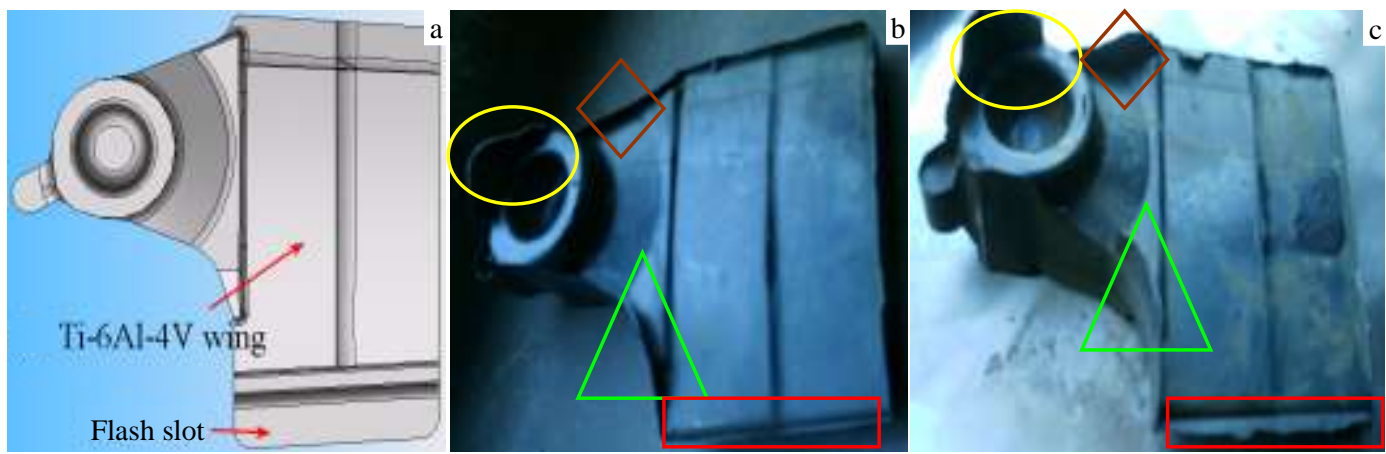

Fig. 8 3D model with flash slot (a); final integral forging figure of the billet A (b) and the billet B (c)

$11 \mathrm{MPa}$ (280 tonnes) for the billet B. For further study, in mass industrial production, the less volume of flash slots may save much more cost and a fast speed may improve efficiency, but they may also bring about many new problems.

\subsection{Microstructures}

The surface morphologies of the two forgings were examined by the JSM-6360LV scanning electron microscope (SEM). Fig.9 demonstrates the typical microstructures (as mentioned results by Luo and $\mathrm{Ye}^{[10]}$ ) of isothermal forging specimens $\mathrm{A}$ and $\mathrm{B}$ at different temperatures in the two phase region of $\alpha+\beta$. As shown in Fig.9, hydrogen embrittlement, alpha embrittlement cannot occur at the superficial zone. It is maybe because that, hydrogen could be retained at temperatures up to $980{ }^{\circ} \mathrm{C}$ due to the formation of an oxidized film on the specimen surface by Zhao and Ding ${ }^{[17]}$. The common
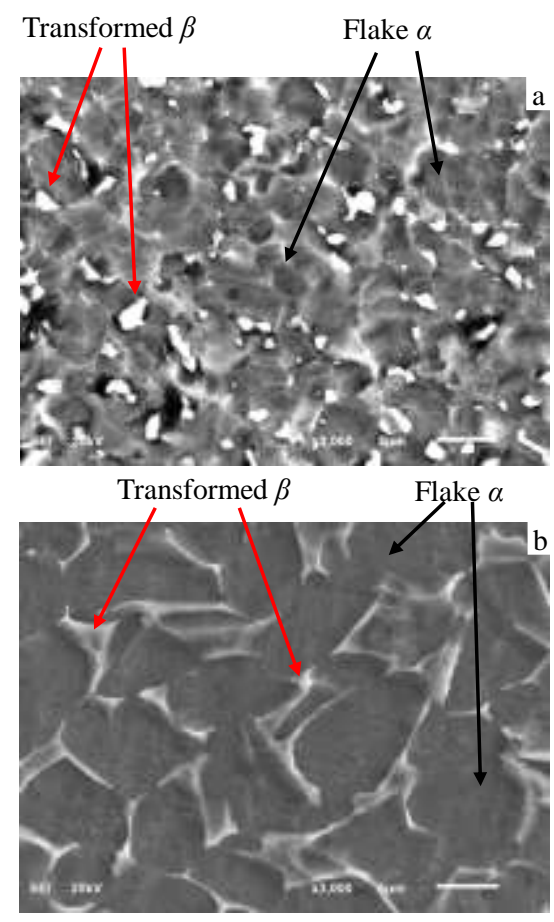

Fig. 9 Microstructures of deformed samples: (a) the billet $\mathrm{A}$ at $950^{\circ} \mathrm{C}$ and (b) the billet $\mathrm{B}$ at $900{ }^{\circ} \mathrm{C}$ characteristic of both micrographs was that flake $\alpha$ grains were transformed to $\beta$ in a matrix. However, it was apparent that the progress of transformation process diminished with the decrease in temperature, and $\beta$ grains at $950{ }^{\circ} \mathrm{C}$ were more distinguishable and a bit coarser than that at $900{ }^{\circ} \mathrm{C}$. Furthermore, as a result of $\alpha$ to $\beta$ transformation, the lower volume fraction of $\alpha$ grains at higher temperatures degraded the effect of transformation, and led to more laggard subsidence of flow stress. It was noted that smaller flow stress at a higher temperature and a lower slider pressure, but in fact, the billet $\mathrm{A}$ at $950{ }^{\circ} \mathrm{C}$ was a higher slider pressure than the billet B at $900{ }^{\circ} \mathrm{C}$ (as mentioned in 3.2) mainly because of much more volumes of the flash slug.

\section{Conclusions}

1) At $950{ }^{\circ} \mathrm{C}$, by the isothermal forging process, the titanium alloy wing component with complex shape was successfully forged, and more reasonable distribution of metal flow, accurate size, clear profile and high-quality surfaces were required.

2) Compared with the titanium wing formed by conventional methods, the wing made by isothermal forging remarkably improves mechanical performances, and material utilization increases $13 \%$ to $50 \%$, which greatly meets the demand of fine forging products in the aerospace engineering and automobile industry.

3) During the isothermal forging process of Ti-6Al-4V, the flake $\alpha$ grains at $950{ }^{\circ} \mathrm{C}$ is transformed to $\beta$ grains in the matrix; while the progress of transformation diminishes when the forging temperature decreases to $900^{\circ} \mathrm{C}$.

\section{References}

1 Srivastava A K, Iverson J. International Manufacturing Science and Engineering Conference[C]. Yichang: ICMSE, 2010, 1: 401

2 Luo J, Li M Q, Yu W X. Rare Metal Materials and Engineering[J], 2010, 39(8): 1323

3 Yu Y S, Xie L S, Chen M H et al. Surface \& Coatings Technology[J], 2015, 280: 122

4 Wu G Q, Cheng X, Sha W et al. Materials Chemistry and 
Physics[J], 2016, 175: 125

5 Uhlmann E, Kersting R, Klein T B et al. Procedia CIRP[J], 2015, 35: 55

6 Yang Z Y, Zheng X H, Wu Y et al. Journal of Alloys and Compounds[J], 2016, 680: 462

7 Chumachenko E N, Portnoi V K, Paris L et al. Journal of Materials Processing Technology[J], 2005, 170: 448

8 Zhao Z L, Guo H Z, Yao Z K et al. Journal of Materials Processing Technology[J], 2012, 212: 1495

9 Shi Z F, Guo H Z, Liu R et al. Transactions of Nonferrous Metals Society of China[J], 2015, 35: 72

10 Luo J, Ye P, Li M Q et al. Materials and Design[J], 2015, 88: 32

11 Ji H Z, Yuan L, Shan D B. Materials Research Innovations [J],
2011, 15: S466

12 Yang X M, Guo H Z, Yao Z K et al. Materials Science \& Engineering $A[\mathrm{~J}], 2016,673: 355$

13 Volkhonskii A O, Blinkov I V, Anikin V N et al. Russian Journal of Nonferrous Metals[J], 2015, 56(6): 633

14 Sun S, Brandt M, Dargusch M S. International Journal of Machine Tools and Manufacture [J], 2009, 49: 561

15 Chena G, Renb C, Qina X et al. Materials and Design[J], 2015, 83: 598

16 Chakrabarty J. Theory of Plasticity[M]. Elsevier ButterworthHeinemann, 2006: 72

17 Zhao J, Ding H, Zhao W. Journal of Alloys and Compounds [J], 2013, 574: 407

\title{
复杂结构钛合金机翼的等温锻造试验研究
}

\author{
蒋红琰 ${ }^{1}$, 程 峰 $^{2}$ \\ (1. 江苏科技大学, 江苏 张家港 215600) \\ (2. 江南大学, 江苏 无锡 214122)
}

\begin{abstract}
摘 要: Ti-6Al-4V 合金是应用于航空和汽车工业领域的关键结构件, 但是它硬度高, 难加工, 价格昂贵, 且大尺寸毛坏时材料利用率 很低, 采用传统加工方法很难满足现代制造的需求。针对 Ti-6Al-4V 合金机翼, 采用铅模拟实验优化了合理的锻坯形状, 并引入了一种 闭式等温锻造工艺, 研究了等温锻造 Ti-6Al-4V 合金机翼的成形能力、机械性能和工艺参数等性能。结果表明: 与传统加工的钛合金机 翼相比, 等温锻造机翼显著的改善了零件的机械性能, 材料利用率从 $13 \%$ 提高到 50\%; 在 $950{ }^{\circ} \mathrm{C}$ 的等温锻造温度下, Ti- $6 \mathrm{Al}-4 \mathrm{~V}$ 基体内 片状 $\alpha$ 相逐渐转变为 $\beta$ 相, 而当锻造温度为 $900{ }^{\circ} \mathrm{C}$ 时, 这种相变效果呈减弱趋势。
\end{abstract}

关键词: 钣合金; 复杂结构机翼; 等温锻造; 试验研究

作者简介: 蒋红琰, 女, 1980 年生, 硕士, 实验师, 江苏科技大学机电与动力工程学院, 江苏 张家港 215600, E-mail: jhy8037@163.com 